\title{
Childhood Obesity in Primary School Children of Middle and Upper-Middle Income Group in the Capital City of Bangladesh
}

\author{
Shuhana Sultana1, Farzana Saleh ${ }^{2 *}$, Liaquat Ali ${ }^{3}$ \\ ${ }^{1}$ Department of Health Promotion \& Health Education, Bangladesh University of Health Sciences (BUHS), \\ Dhaka, Bangladesh \\ ${ }^{2}$ Department of Community Nutrition, Bangladesh University of Health Sciences (BUHS), Dhaka, Bangladesh \\ ${ }^{3}$ Department of Biochemistry \& Cell Biology, Bangladesh University of Health Sciences (BUHS), Dhaka, \\ Bangladesh \\ Email: ${ }^{*}$ farzanasaleh sumona@yahoo.com
}

Received 10 July 2015; accepted 5 October 2015; published 8 October 2015

Copyright @ 2015 by authors and Scientific Research Publishing Inc.

This work is licensed under the Creative Commons Attribution International License (CC BY). http://creativecommons.org/licenses/by/4.0/

(c) (i) 0 pen Access

\begin{abstract}
Background: No published information is available on the status of childhood obesity in Bangladeshi primary school children of urban middle and upper-middle income group. The aim of the study was to explore the proportion of childhood obesity in the primary school children of middle and upper-middle income group in capital city and to gather information on their dietary pattern and physical activity. Methods: One hundred and fifty children (age $9 \pm 1$ years, height (ht) $118 \pm$ $20 \mathrm{~cm}$, weight (wt) $36 \pm 8 \mathrm{~kg}$, wt/ht\% $126 \pm 24$, mean \pm SD) were selected purposively from the primary schools of Dhaka city. On the basis of predefined scoring, subjects were classified as underweight, normal, overweight and obese if their weight-for-height values were $<90 \%, 91 \%$ $110 \%, 111 \%-120 \%$ or $>120 \%$ of median values for Bangladeshi children respectively. Dietary intake and energy expenditure of the study subjects were calculated by standard techniques. Results: The proportion of childhood overweight and obesity was $52 \%$ and $20 \%$. The proportion of overweight and obesity was higher (78\%) among girls compared to boys (54\%). Similarly, height, weight and other anthropometrics indices were significantly $(p<0.05)$ higher in girls compared to boys. The daily intake of carbohydrate and protein was significantly $(p<0.05)$ higher among obese group. Total energy balance was significantly correlated with weight-for-height $\%(r=0.541, p$ $=0.0001$ ) . Conclusions: A higher proportion of overweight and obesity had been found in girls' children than their counter parts in this study. Positive energy balance with higher energy intake from carbohydrate and fast/processed food culture habit were found among primary school children of middle and upper-middle income group in the capital city of Bangladesh.
\end{abstract}

How to cite this paper: Sultana, S., Saleh, F. and Ali, L. (2015) Childhood Obesity in Primary School Children of Middle and Upper-Middle Income Group in the Capital City of Bangladesh. Food and Nutrition Sciences, 6, 1185-1192. 


\title{
Keywords
}

\author{
Obesity, Overweight, Weight, Fast Foods Culture, Nutrition, Primary School Children, Urban, \\ Capital City, Dhaka, Bangladesh
}

\section{Introduction}

Obesity is now recognized as a major cause of mortality and morbidity around the world. Its prevalence is increasing at an alarming rate regardless of age and geographical variation. According to WHO (2008) [1], there are 1 billion overweight people in the world, of whom 300 million are obese. In recent decades childhood obesity has become a serious public health problem because of its strong association with adulthood obesity and the related adverse health consequences. Genetic, environmental and developmental factors have been shown to contribute significantly to the development of obesity. Urbanization, unhealthy diets and increased sedentary lifestyles have contributed to the increased prevalence of childhood obesity, particularly in developing countries [2]. The South-East Asia region has started to experience a remarkable change in child obesity with the prevalence of overweight rapidly rising in recent years and the estimated prevalence of excess of bodyweight in school-age children in 2010 has been found 23\% (including obese) [3]. In Pakistan, 6\% obese and 8\% overweight children were found and of all obese children, 70\% belonged to the higher socio-economic status (SES) group [4]. In Chennai, India, more than 22\% obese school children belonged to higher SES, 15\% to middle SES and only 4.5\% to low SES groups [5]. In Thailand [6], the prevalence of childhood obesity had been found to be $10.8 \%$ in urban most wealthy region, and in Beirut [7], the prevalence of overweight was found $26 \%$ both in boys and girls. In Dhaka, a pilot study has been conducted on the prevalence of obesity among affluent school children and adolescents. About $17.9 \%$ obese and $23.6 \%$ overweight were found [8] in pilot study. Different studies demonstrated that children from a higher socio-economic status were more vulnerable to develop obesity than others [9] [10].

Childhood obesity is associated with several metabolic and endocrine derangements including hyperinsulinaemia, glucose intolerance, hypertension and dyslipidaemia. Early and appropriate intervention is to be needed for preventing childhood obesity. Studies on childhood obesity are well explored in developed countries though almost absent in developing countries. Limited data are available in our country on the childhood obesity and their lifestyle pattern that are belonging to middle and upper-middle class. The present baseline study was undertaken to explore the proportion of childhood obesity and to gather information on their dietary pattern and lifestyle among primary school children of middle and upper-middle income group in the capital city of Bangladesh.

\section{Methods}

Under a cross-sectional design 150 children (age between 6 - 11 years) were collected purposively from the selected primary schools of middle and upper-middle income group. About 150 the minimum required sample size was calculated by using formula: $\mathrm{n}=\mathrm{Z}^{2} \mathrm{pq} / \mathrm{d}^{2}$ (where, $\mathrm{n}=$ the required sample size, $\mathrm{p}=$ the expected proportion, $Z=95 \%$ confidence interval and $d=5 \%$ error). In Thailand the prevalence of childhood obesity was $10.8 \%$ [6]. Therefore, $\mathrm{p}=10.8 \%$ had been taken at the expected proportion. Subjects who had chronic diseases and were unable to answer short list of simple questions were excluded from the study. The history of the subject and their parents were collected by an interviewer-administered preset questionnaire. Pre-test were conducted. A standard questionnaire was constructed in local language and interview was administrated in the school. A medium sized four-part questionnaire was designed by the researcher. The questionnaire included socio demographic data, anthropometry parameters, dietary intake and lifestyle pattern of the children. Body weight and height was measured by using appropriate techniques. Childhood obesity was determined using the weight and height measurements and classified as underweight $(<90 \%)$, normal $(90 \%-110 \%)$, overweight $(110 \%-120 \%)$ or obese $(>120 \%)$ [9]. This method was chosen because it is relatively non-invasive and inexpensive, reflecting body weight relative to height, thus more closely reflecting body fatness than other methods. It is sensitive to current nutritional status and relatively independent. Mid upper-arm circumference (MUAC) was measured using standard procedure. The dietary intake of the subjects was calculated by using 24 hour recall method [11]. Energy 
expenditure was calculated by factorial method using lifestyle data of the children and energy balance was calculated by subtracting the total energy expenditure from the total daily energy intake [12]. The statistical tests were considered significant at a level of $\leq 5 \%(\leq 0.05)$. Student t-test, ANOVA and correlation were performed for statistical analysis. Socioeconomic classifications in this study were made according to the 2006 per capita Gross National Income (GNI) and according to World Bank (WB) calculations [13]. The groups were: low-income, $\$ 905$ or less (BDT $\leq 5360$ ); lower-middle-income, \$906 - \$3595 (BDT 5361 - 21,270); upper-middle-income, \$3596 - \$11,115 (BDT 21,271 - 65,761); and high-income, $\$ 11,116$ or more (BDT $\geq 65,762$ ). Ethical approval was obtained from the local ethical and research review committee. Informed written consent was taken from all respondents after full explanation of the nature, purpose and all procedures used for the study. Confidentiality of participant was maintained throughout the study period.

\section{Results}

Mean age of the children were $8.18 \pm 1.13$ years, among them 78 (52\%) and 72 (48\%) were boys and girls. Majority (98\%) of the father and 69\% mother of the subjects were graduate \& above. About $64 \%$ fathers and $77 \%$ mothers of the subjects were overweight and obese. Most of the children (88.7\%) belonged to upper-middle and high income family. Only $11.3 \%$ children were in low-middle income group (Table 1).

Table 1. Characteristics of the children $(n=150)$.

\begin{tabular}{|c|c|}
\hline Variables & \\
\hline Age, years & $8.18 \pm 1.13$ \\
\hline \multicolumn{2}{|l|}{ Sex } \\
\hline Boys & 78 (52\%) \\
\hline Girls & $72(48 \%)$ \\
\hline \multicolumn{2}{|l|}{ Education of mother } \\
\hline Illiterate-primary & $0(0 \%)$ \\
\hline SSC-HSC & 46 (31\%) \\
\hline Graduate \& above & $104(69 \%)$ \\
\hline \multicolumn{2}{|l|}{ Education of father } \\
\hline Illiterate-primary & $0(0 \%)$ \\
\hline SSC-HSC & $3(2 \%)$ \\
\hline Graduate $\&$ above & 147 (98\%) \\
\hline BMI of mother $\left(\mathrm{kg} / \mathrm{m}^{2}\right)$ & $25 \pm 3.78$ \\
\hline Underweight (<18.5) & $5(3.3 \%)$ \\
\hline Normal (18.5 - 22.9) & $29(19 \%)$ \\
\hline Overweight (23 - 27.5) & $90(60 \%)$ \\
\hline Obese $(>27.5)$ & $26(17 \%)$ \\
\hline BMI of father $\left(\mathrm{kg} / \mathrm{m}^{2}\right)$ & $23.4 \pm 2.86$ \\
\hline Underweight (<18.5) & $7(4.7 \%)$ \\
\hline Normal (18.5 - 22.9) & 47 (31.3\%) \\
\hline Overweight (23 - 27.5) & $84(56 \%)$ \\
\hline Obese $(>27.5)$ & $12(8 \%)$ \\
\hline \multicolumn{2}{|l|}{ Parents monthly income (BTD/month) } \\
\hline Low income $(<3560)$ & $0(0 \%)$ \\
\hline Lower middle (3560 - 21,270) & $17(11.3 \%)$ \\
\hline Upper middle (21,271 - 65,761) & 96 (64\%) \\
\hline High income $(>65,762)$ & $37(24.7 \%)$ \\
\hline
\end{tabular}

Results are expressed as mean \pm SD and number (\%). 
Figure 1 showed the weight for height category of the children according to sex. Among boys $44 \%$ were obese and $10 \%$ were overweight. Only $30 \%$ boys had weight within the normal range, while $17 \%$ were underweight. However, among girls $61 \%$ were obese and $17 \%$ overweight respectively. About $19 \%$ girls were in normal range and only $3 \%$ were underweight.

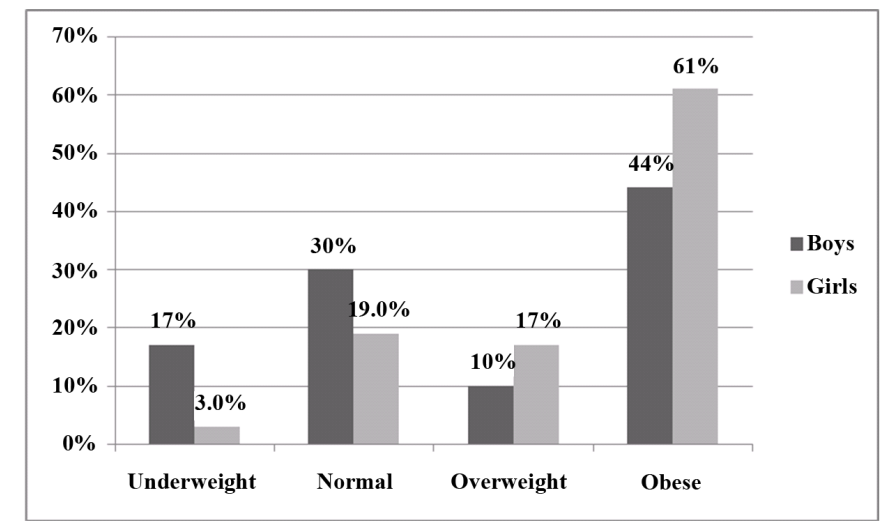

Figure 1. Weight status category of the children $(\mathrm{n}=150)$.

A significant difference was found between boys and girls in weight ( $\mathrm{kg}, 33 \pm 7$ vs $36 \pm 9$, p $=0.019$ ), weight for height (\%, $117.2 \pm 26.2$ vs $134.7 \pm 28.8, \mathrm{p}=0.0001)$ and $\operatorname{MUAC}(\mathrm{cm}, 22.6 \pm 4.4$ vs $24.5 \pm 5.5, \mathrm{p}=0.018)$ (Table 2).

Table 2. Comparison of the height, weight and other anthropometrics indices of the children according to sex $(n=150)$.

\begin{tabular}{ccccc}
\hline Sex & Weight in $\mathbf{~ k g}$ & Height in meter & wt/ht $\%$ & MUAC $(\mathbf{c m})$ \\
\hline Boy $(\mathrm{n}=78)$ & $33 \pm 7$ & $1.23 \pm 0.16$ & $117.2 \pm 26.2$ & $22.6 \pm 4.4$ \\
Girl $(\mathrm{n}=72)$ & $36 \pm 9$ & $1.18 \pm 0.18$ & $134.7 \pm 28.8$ & $24.5 \pm 5.5$ \\
$\mathrm{t} / \mathrm{p}$ value & $2.36 / 0.019^{*}$ & $1.7 / 0.08$ & $3.87 / 0.0001^{*}$ & $2.39 / 0.018^{*}$ \\
\hline
\end{tabular}

Results are expressed as mean $\pm S D$. Wt/ht\% = weight for height, MUAC = Mid Upper Arm Circumference. Student's t-test is performed as the test of significance. ${ }^{*} \mathrm{p}<0.05$ are taken as level of significance.

Table 3 showed the average daily intake of macro nutrients by the children according to their weight status Table 3. Macro nutrient intake of the children according to weight status category $(n=150)$.

\begin{tabular}{cccc}
\hline Weight status category & CHO intake $(\mathrm{g} /$ day $)$ & Protein intake (g/day) & Fat intake (g/day) \\
\hline All $(\mathrm{n}=150)$ & $340(141-1667)$ & $101(26-449)$ & $93(40-263)$ \\
Underweight $(<90)(\mathrm{n}=15)$ & $225(141-463)$ & $71(26-183)$ & $76(40-147)$ \\
Normal $(91-110)(\mathrm{n}=37)$ & $274(161-623)$ & $88(48-236)$ & $99(40-205)$ \\
Overweight $(111-120)(\mathrm{n}=20)$ & $315(205-655)$ & $87(50-242)$ & $84(53-144)$ \\
Obese $(>120)(\mathrm{n}=78)$ & $422(227-1667)$ & $122(60-449)$ & $94(41-263)$ \\
F/p & $8.7 / 0.0001^{*}$ & $8.6 / 0.001^{*}$ & \\
& $0.9 / 0.04^{*}$ \\
Underweight vs Obese & 0.003 & & 0.078 \\
Normal weight vs Obese & 0.0001 & 0.006 & $\mathrm{~ns}$ \\
Overweight vs Obese & 0.049 & 0.0001 & $\mathrm{~ns}$ \\
\hline
\end{tabular}

Results are expressed as median (range). One-way ANOVA (Post Hoc Bonferroni) is performed as the test of significance. ${ }^{*} \mathrm{p}<$ 0.05 is taken as level of significance. 
category. Obese group had significantly $(\mathrm{p}<0.05)$ higher intake of carbohydrate and protein compared to underweight, normal and overweight groups.

Nearly half of the children (50\%) inspired to take sandwich, burger, fried chicken and nodules 1 - 3 times per week. About 63\% liked to eat sweet more than 6 times per week (Table 4).

Table 4. Pattern of fast foods consumption among the children $(n=150)$.

\begin{tabular}{ccccc}
\hline Consumption of fast food items & \multicolumn{4}{c}{ Frequency (\%) } \\
\hline \multirow{2}{*}{ Sandwich } & $1-3$ times/wk & $4-6$ times/wk & $>6$ times/wk & Never \\
Burger & $87(58 \%)$ & $23(15 \%)$ & $9(6 \%)$ & $31(21 \%)$ \\
Fried chicken & $80(53 \%)$ & $27(18 \%)$ & $11(7 \%)$ & $32(21 \%)$ \\
Fried nodules & $89(59 \%)$ & $28(19 \%)$ & $6(4 \%)$ & $27(18 \%)$ \\
Chips & $66(44 \%)$ & $49(33 \%)$ & $23(15 \%)$ & $12(8 \%)$ \\
Sweet & $48(32 \%)$ & $49(33 \%)$ & $12(8 \%)$ & $41(27 \%)$ \\
\hline
\end{tabular}

Results are expressed as number (\%).

Energy intake was significantly ( $<0.5$ ) higher among the obese group compared to underweight, normal and overweight groups. Similarly, energy expenditure of obese group was significantly $(\mathrm{p}<0.05)$ higher compared to other three groups (Table 5).

Table 5. Energy intake, energy expenditure of the children according to weight status category ( $n=150)$.

\begin{tabular}{ccc}
\hline Weight Status Category & Energy Intake $(\mathrm{kcal} /$ day $)$ & Energy Expenditure (kcal/day) \\
\hline All $(\mathrm{n}=150)$ & $3960(1738-11,466)$ & $2204(1585-3276)$ \\
Underweight $(<90)(\mathrm{n}=15)$ & $2769(1991-4579)$ & $1934(1584-2264)$ \\
Normal $(91-110)(\mathrm{n}=37)$ & $3514(1738-6722)$ & $1961(1660-2512)$ \\
Overweight $(111-120)(\mathrm{n}=20)$ & $3307(2277-5460)$ & $2167(1773-2636)$ \\
Obese $(>120)(\mathrm{n}=78)$ & $4060(2364-11,466)$ & $2336(1998-3276)$ \\
F/p & $7.36 / 0.0001^{*}$ & $33.89 / 0.0001^{*}$ \\
Underweight vs Obese & p-value & 0.0001 \\
Normal weight vs Obese & 0.002 & 0.0001 \\
Overweight vs Obese & 0.016 & 0.0001 \\
\hline
\end{tabular}

Results are expressed as median (range). One-way ANOVA (Post Hoc Bonferroni) is performed as the test of significance. ${ }^{*} \mathrm{p}<$ 0.05 is taken as level of significance.

Weight for height (Wt/ht) showed a significant and positive association with intake of carbohydrate $(r=0.556$, $\mathrm{p}=0.0001)$, animal protein $(\mathrm{r}=0.499, \mathrm{p}=0.0001)$ and animal fat $(\mathrm{r}=0.29, \mathrm{p}=0.0001)$ (Table 6).

Table 6. Energy intake, energy expenditure of the children according to weight status category $(\mathrm{n}=150)$.

\begin{tabular}{cc}
\hline Variables & r/p \\
\hline Total animal protein & $0.499 / 0.0001^{* *}$ \\
Total animal fat & $0.290 / 0.0001^{* *}$ \\
CHO intake & $0.556 / 0.0001^{* *}$ \\
\hline
\end{tabular}

**Correlation is significant at the 0.01 level (2-tailed). 
Figure 2 showed the significant and positive association between weight for height (wt/ht\%) and energy balance $(r=0.541, p=0.0001)$.

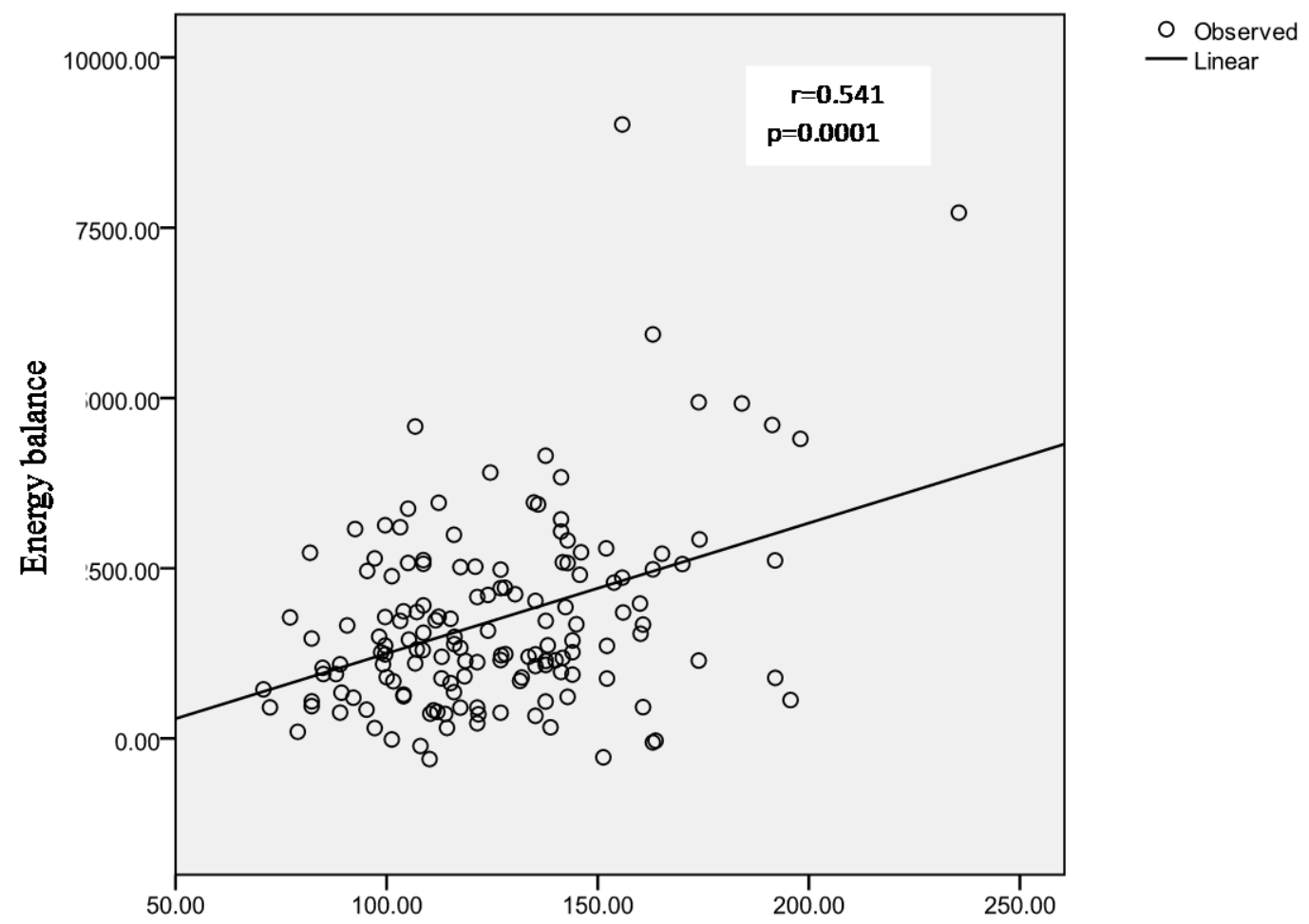

Figure 2. Association between energy balance and weight for height (\%) among the children.

\section{Discussion}

Dhaka is the capital city of Bangladesh, which is more likely to have experienced greater economic transition than the adjacent urban areas. The proportion of overweight and obesity $65 \%$ in this study was higher than the prevalence of childhood obesity reported in the pilot study [8] among affluent school children and adolescents in Dhaka city. Other urban studies were carried out in Pakistan [4], India [5] and Thailand [6] where the prevalence was around $14 \%, 22 \%$ and $10.8 \%$ respectively and in Beirut [7], the prevalence of overweight was found $26 \%$ both in boys and girls. Increasing economic development in a region is often associated with increasing prevalence of obesity, not only in industrialized countries but also in newly developed nations such as Brazil [14] as well as developing country like Pakistan [4] and India [5]. The international literature has portrayed developing countries as having relatively low levels of obesity coexisting with high prevalence of underweight [10].

In this study, the proportions of overweight and obesity were more prevalent in girls (17\% and $61 \%$ respectively) compared to boys (10\% and $44 \%$ respectively), using cut-off points for weight for height [9]. Weight (p $=0.019)$ and weight-for-height $(\mathrm{p}=0.0001)$ were significantly higher in girls compared to boys, as with this age group girls are taller than boys. Similar result was found in MUAC $(p=0.018)$. However, an Indian study showed that height and weight were higher in boys than those in girls $(\mathrm{p}<0.001)[5]$.

Energy comes from particularly carbohydrate, protein and fat intake. These are the major contributors to the development of overweight and obesity. In the present study, mean carbohydrate and protein intake were significantly ( $<0.05$ ) higher among the overweight and obese children compared to normal and underweight children. Moreover, mean fat intake of the obese group was higher compared to the rest of three groups but not significant. Significant $(\mathrm{p}<0.05)$ results were found in energy intake among obese children. The protein $(r=0.499$, $\mathrm{p}=0.0001)$, fat $(\mathrm{r}=0.29, \mathrm{p}=0.0001)$ and carbohydrate $(\mathrm{r}=0.556, \mathrm{p}=0.0001)$ intakes were significantly and positively associated with the children's weight for height. Though in Beirut study [7], no significant association was found between nutrient intake and children's BMI, in present study, total energy balance was found significantly positively correlated with weight-for-height $(r=0.541, p=0.0001)$. 
Environmental factors such as high-energy intake, particularly fat intake, sex, age, household family income, patents education and lifestyle are the major contributors to the development of overweight and obesity. And our study also showed that having family history of obesity increased the risk of child obesity, but not significantly and due to small sample size the results might not get significant. Socio-economic indicators such as educational level, employment status and paternal income did not significantly differ on children's weight status in present study though in Pakistan [4], 70\% obese children belonged to the higher socio-economic status (SES) group and in India [5], >22\% obese children to higher SES, 15\% to middle SES and only $4.5 \%$ to low SES groups. However, access of more fast/processed foods and lack of physical activities facilities among the urban children contributed to the higher proportion of overweight and obesity and as well as feeding pattern, food habits and lifestyle including physical activity shaped by obese parents may be the foundation of later eating style and life pattern leading to obesity.

Childhood eating habits and exercise can be more easily modified than adult habits by adopting a formal exercise program, or simply becoming more active. Balanced diet with moderate caloric restriction, especially reduced dietary fat, has been also used successfully in treating obesity [15].

\section{Conclusions}

The present study provides baseline data regarding the status of childhood obesity in primary school children of middle and upper-middle income group in Dhaka. The result of the current study may organize the foundation of awareness to develop policies in order to address the challenges to prevent childhood obesity and to modify their eating habit and lifestyle.

\section{Limitations}

Due to limited time frame and resources, we would not collect a much larger sample size in order to generalize our results to the whole Bangladeshi population, and we could not collect detail physical activity history of the children. Another limitation of this study was its cross-sectional design. The ability to make causal inference from the findings was thus limited.

\section{Acknowledgements}

We are highly acknowledged our colleague Ms Samira Humaira Habib, Diabetic Association of Bangladesh and students of Food \& Nutrition, Bangladesh Home Economics College, Dhaka. We also acknowledge the Diabetic Association of Bangladesh for their technical support.

\section{Conflict of Interest}

The authors report no conflicts of interest.

\section{References}

[1] World Health Organization (2008) Global Strategy on Diet, Physical Activity and Health. The Organization, Geneva.

[2] Alberti, K.G., Kimmet, P. and Shaw, P. (2006) Metabolic Syndrome-A New Worldwide Definition. A Consensus Statement from the International Diabetic Federation. Diabetic Medicine, 23, 469-480. http://dx.doi.org/10.1111/j.1464-5491.2006.01858.x

[3] Wang, Y. and Lobstein, T. (2006) Worldwide Trends in Childhood Overweight and Obesity. International Journal of Pediatric Obesity, 1, 11-25. http://dx.doi.org/10.1080/17477160600586747

[4] Warraich, H.J., Javed, F., Faraz-ul-Haq, M., Khawaja, F.B. and Saleem, S. (2009) Prevalence of Obesity in School Going Children of Karachi. PloS ONE, 4, e4816. http://dx.doi.org/10.1371/journal.pone.0004816

[5] Ramachandran, A., Snehalatha, C., Vinitha, R., Thayyil, M., Kumar, C.K., Sheeba, L., et al. (2002) Prevalence of Overweight in Urban Indian Adolescent School Children. Diabetes Research and Clinical Practice, 57, 185-190. http://dx.doi.org/10.1016/S0168-8227(02)00056-6

[6] Langendijk, G., Wellings, S., Wyk, M., Thomson, S.J., McComb, J. and Chusilp, K. (2003) The Prevalence of Childhood Obesity in Primary School Children in Urban Khon Kaen, Northeast Thailand. Asia Pacific Journal of Clinical Nutrition, 12, 66-72.

[7] Jaber, P., Sikias, P., Khater-Menassa, B., Boddoura, R. and Awada, H. (2005) Overweight Children in Beirut: Preva- 
lence Estimates and Characteristics. Child: Care, Health \& Development, 31, 159-165. http://dx.doi.org/10.1111/j.1365-2214.2004.00458.x

[8] Mohsin, F., Tayyeb, S., Baki, A., Sarker, S., Zabeen, B., Begum, T., et al. (2010) Prevalence of Obesity among Affluent School Children in Dhaka. Mymensingh Medical Journal, 19, 549-554.

[9] Mon-Suwan, L. and Geater, A.F. (1996) Risk Factors for Childhood Obesity in a Transitional Society in Thailand. International Journal of Obesity, 20, 697-703.

[10] Stunkard, A., Aquili, E., Fox, S. and Filion, R.D.L. (1972) Influence of Social Class on Obesity and Thinness in Children. Journal of the American Medical Association, 192, 97-102.

[11] Mumu, S.J., Saleh, F., Afnan, F., Akhter, A. and Ahmed, K.R. (2009) Pattern of Dietary Intake among Newly Diagnosed Type 2 Diabetic Subjects with Hypercholesterolemia. Pakistan Journal of Nutrition, 8, 721-724. http://dx.doi.org/10.3923/pjn.2009.721.724

[12] Afnan, F., Ahmed, K.R., Akter, S., Mumu, S.J., Akter, F., Chaudhury, H.S., et al. (2009) Effect of Non Pharmacological Intervention on Dietary Practice, Energy Expenditure and Biomedical Parameters of Hypercholesterolemic Type 2 Diabetic Subjects. Ibrahim Medical College Journal, 3, 75-77.

[13] Haque, N. (2011) The Middle-Income Matrix. The Daily Star, 24 March 2011, 11-18.

[14] Monteiro, C.A., Mondini, L., De Souza, A.L. and Popkin, B.M. (1995) The Nutrition Transition in Brazil. European Journal of Clinical Nutrition, 49, 105-113.

[15] Dietz, W.H. (1983) Childhood Obesity. Susceptibility, Cause, and Management. Journal of Pediatrics, 103, 676-686. http://dx.doi.org/10.1016/S0022-3476(83)80457-0 